\title{
Discurso de la Publicidad Comercial Riverense a Principios del Siglo XX.
}

\author{
O Discurso da Publicidade Comercial em Rivera no Início do Século XX.
}

\section{Discourse of the Advertising of Rivera in the Early Twentieth Century}

\author{
Paula Bastón ${ }^{1}$ \\ Santiago Silveira ${ }^{2}$
}

\begin{abstract}
Resumo
Como parte da Equipe de Investigação em Estudos de Fronteira do CeRP do Norte, em parceria com o Museu do Patrimônio Regional, optamos como tema a ser explorado a partir de documentação de arquivo o estudo sobre a publicidade na cidade de Rivera. Este projeto de investigação centra-se no estudo da publicidade comercial entre os anos de 1914 e 1920. Nela se está fazendo um seguimento dentro do período de tempo que a pesquisa está enquadrada, observando as alterações introduzidas, tendo em conta o contexto histórico no qual estava inserida a cidade de Rivera, o design e o conteúdo da publicidade, e a procura de outras fontes e ferramentas. Através de este estudo, se pretende determinar o impacto da publicidade sobre a sociedade riverense do início do século XX, assim se estará produzindo um diagnóstico da sensibilidade da época e espaço a estudar, e através disto lograr uma interpretação do espaço da fronteira ao qual estamos comprometidos. O interesse deste trabalho e fornecer relevância para os eventos históricos da região que até agora permanecem maiormente esquecidos.
\end{abstract}

Palvras-chave: Fronteira. Sociedade. Publicidade

Resumen

Como parte del Equipo Multidisciplinario de Estudios de Frontera del CeRP del Norte, en convenio con el Museo del Patrimonio Regional, como temática a ser explorada a partir de documentos se optó por el estudio de la publicidad en la ciudad de Rivera. Este proyecto de investigación se centra en el estudio de la publicidad comercial entre 1914 y 1920. Se está haciendo un seguimiento dentro del período de tiempo en el cual se enmarca la investigación, observando los cambios que presenta, teniendo en cuenta el contexto en el que se encontraba inserta la ciudad de Rivera, el diseño y contenido de la publicidad, y la búsqueda de otras fuentes y herramientas. A través de este estudio, se determinará el impacto de la publicidad en la sociedad riverense de principios del siglo XX, así se estará produciendo un diagnóstico de la sensibilidad de dicho espacio y tiempo a estudiar, y a través de éste se interpretará el espacio de frontera al cual estamos abocados. El interés de este trabajo es proporcionar relevancia a sucesos históricos en la región que hasta ahora permanecen mayormente en el olvido.

Palabras clave: Frontera. Sociedad. Publicidad.

\section{Abstract}

As part of the Multidisciplinary Study Team of Frontier, in agreement with the Regional Heritage Museum, as a theme to be explored from documents chose the study of advertising in the city of Rivera. This research project focuses on the study of commercial advertising between 1914 and 1920. It is monitoring within the period of time in which the research is framed, observing the changes introduced, taking into account the context in which

\footnotetext{
${ }^{1}$ Centro Regional de Profesores del Norte. Rivera, Uruguai. paulibaston@gmail.com

${ }^{2}$ Centro Regional de Profesores del Norte. Rivera, Uruguai. silveiraost24@gmail.com
} 
he was inserted town of Rivera, the design and content of advertising, and search for other sources and tools. Through this study, the impact of advertising on the riverense society of the early twentieth century will be determined and will be producing a diagnosis of the sensitivity of the space and time to study, and through this space boundary shall be construed to which we are committed. The interest of this work is to provide relevance to historical events in the region that so far remain largely forgotten.

Keywords: Advertising. Society. Frontier.

\section{1- Introducción}

Este estudio pretende abordar la publicidad comercial riverense en el contexto que comprende los años 1914 a 1920. Nos proponemos identificar las características de la sociedad riverense a través del análisis de su discurso; para interpretar la publicidad de la época, es imprescindible tener en cuenta la coyuntura internacional, y de la región en un espacio temporal más amplio que el período a estudiar.

A fines del siglo XIX y principios del siglo XX, el sistema capitalista se expande bajo su etapa financiero-monopólica, buscando nuevas colonias, por lo tanto también se denomina la época del Imperialismo. América Latina no es ajena a esta situación, en lo que se llama el período de Modernización en nuestro continente, Inglaterra realiza fuertes inyecciones de capital, también en menor medida Francia y el emergente Estados Unidos (HOBSBAWM, 1973).

Las inversiones extranjeras en el continente, hacen que este sea una periferia dependiente de los centros (potencias industrializadas). Desde la óptica de Aníbal Quijano, entre otros autores destacan que no es en el contexto citado anteriormente en el que se forma una sociedad dependiente, sino que ya existía desde la época colonial, luego del período de la independencia hubo un desplazo de la península ibérica como centro hegemónico, y éste pasa a ser las nuevas potencias industrializadas (QUIJANO, BERTOLA y OCAMPO, 2013) у (CARDOSO y FALLETO, 2011).

La manifestación por excelencia de la inserción de Latinoamérica en la estructura capitalista es la modernización y esta trae como consecuencia la consolidación de estadosnación, con la consecuente transformación de la economía y la sociedad en su conjunto, algunos de ellos son el desarrollo de los centros urbanos. Desde la época colonial, la urbanización se desarrolla en las zonas costeras atlánticas de Sudamérica, puertos importantes son los de Buenos Aires y Montevideo. La principal actividad de estos centros urbanos era el comercio con los grandes centros. Esta situación da cuenta que el desarrollo de la urbanización se encuentra ligado a zonas de contacto directo con las metrópolis, y se excluye 
al resto del territorio donde la urbanización es insignificante o prácticamente nula (QUIJANO, s/a).

\section{2- Estado del Arte}

De diferentes lecturas acerca del proceso de Modernización en Uruguay, se desprende que el departamento de Rivera y por ende la ciudad misma, tuvo un lento desarrollo de la modernización, por lo menos hasta la última década del siglo XIX y primeras décadas del siglo XX (BARRÁN y NAHUM, 1977a) y como consecuencia de ello existe muy poca producción historiográfica sobre el mismo, pero a su vez se presenta como un fantástico desafío para los que nos embarcamos en dicha tarea de remover el velo del olvido sobre el pasado de la ciudad y región.

Territorio y región son categorías de análisis que forman un binomio, son inseparables. Haesbaert, brinda definiciones de territorio desde diferentes aspectos, en el político es “(...) todo espacio que tiene el acceso controlado; por lo tanto, desde el momento en que se controla espacial y materialmente el acceso de algún flujo (sea de mercancías, de personas o de capital), se está transformando el espacio en un territorio" (HAESBAERT, 2013, p.10). Teniendo en cuenta esta definición, los grupos sociales controlan simbólicamente un territorio, y también de forma cultural a través de una identificación de los mismos con un determinado espacio. En diversos territorios se suelen dar procesos de hibridación cultural, un caso típico es el de América Latina, este espacio se construye desde una mezcla cultural, impuesta en muchos casos, como en el proceso de colonización. En los espacios de frontera, como Rivera, se da interacción e intercambio cultural, que hacen a una sociedad única. Por lo tanto la frontera es un espacio donde sociedades diferentes interactúan, el Estado aún está en proceso de construcción, es por esta razón que las fronteras cambian, son espacios dinámicos. En este territorio, se desarrollan relaciones sociales de producción específicas, características de ese espacio.

Los países latinoamericanos a pesar de proyectar su economía hacia el exterior, también cuentan con un minúsculo comercio interno que se rige por las leyes de la libre oferta y se maneja con las mismas pautas de competencia y consumo (HALPERÍN, 1969). Un claro ejemplo es la inserción de Rivera en la lógica capitalista, con el avance del proceso de modernización comienzan a surgir diversas casas comerciales, fundamentalmente de ramos generales, propiedad en muchos casos de extranjeros, por esta razón comienzan a llegar con mayor frecuencia a la ciudad productos importados a través del puerto de Montevideo (CHIPOLLINO ASEFF, 2014). 

e-ISSN 2016/Atual: 2525-7870 | e-ISSN 2015/2016: 2447-018X

Desde el último cuarto del siglo XIX está en curso la segunda fase del proceso de industrialización, ello implicó profundos cambios en todos los aspectos de la estructura social, generándose así, la necesidad del consumo de masas, según sostienen diversos autores. Con ello, el dar a conocer los nuevos productos a mayor escala, a un público cada vez más amplio, de manera práctica y masiva se convirtió en una necesidad, así surge la industria de la publicidad, herramienta del mercado para fomentar el consumo. El desarrollo del mercado de masas, genera nuevas fuentes de ingreso a ciertos artistas que se dedican a la publicidad. Debido a dicho proceso la prensa se convierte en un transmisor del arte a las clases populares, puesto que la publicidad es diseñada por artistas, y la distribución de prensa escrita en general se realiza a gran escala, ya que es de bajo costo, y su contenido publicitario incita al consumo (HOBSBAWM, 2007).

La prensa a fines del siglo XIX y principios del siglo $\mathrm{XX}$, se caracteriza de la siguiente manera “(...) innovaciones puramente visuales — gruesos titulares, la composición de las páginas, la mezcla del texto y la imagen y, sobre todo, los grandes anuncios- (...) En formas simplificadas por razones técnicas la prensa de masas, (...) transformó el medio de la imprenta (...)” (HOBSBAWM, 2007, p.247).

Además de la caracterización de Hobsbawm acerca de la publicidad, Moles y Costa (2005) sostienen que a principios del siglo XX se da el paso hacía la publicidad científica influenciada por el pragmatismo y la racionalidad imperante en esa época, la imagen del afiche paulatinamente pierde importancia respecto al texto, la publicidad se convierte cada vez más enfocada en la redacción, cobrando más relevancia un texto de carácter retórico y por lo general extenso.

Para poder realizar interpretaciones acerca del discurso de la publicidad también es necesario tener como referencias ciertas consideraciones sobre en análisis de los discursos como Foucault (1970), quién lo plantea cómo una práctica a través de la cual se ejerce la dominación y en este caso la publicidad es un medio por el cual se lucha para ejercerla "(...) el discurso no es simplemente aquello que traduce las luchas o los sistemas de dominación, sino aquello por lo que, y por medio de lo cual se lucha, aquel poder del que quiere uno adueñarse” (FOUCAULT, 1970, p.15) También se pueden identificar varias voces, utilizando para ello el concepto de poliglosia de Bajtín, dos o más voces que hablan en un discurso (BAJTÍN, s/f Apud BURKE, 2004) . El discurso es representativo de una sociedad, en el se expresan conceptos que son compartidos por todos los miembros de un determinado espacio, en este caso un espacio de frontera que posee ciertas características culturales que se 
transmiten a través del lenguaje, para analizarlo desde esta perspectiva se tiene en cuenta la teoría de Stuart Hall (1997).

\section{3- La publicidad como herramienta}

Luego de describir la situación de la prensa mundial, en el período a estudiar es necesario tener en cuenta qué es la publicidad: su concepto es aún debatido y está muy ligado a la propaganda. Será durante el siglo XIX que se producirá un cambio en el significado del término que derivará en su asociación con la comunicación comercial que existe en la actualidad. Según Faraone (1969) la prensa es el medio de comunicación masivo más antiguo, su aparición en Uruguay es de larga data, pero recién entrará en la era de la producción masiva en 1863, cuando el diario El Siglo comience a utilizar una máquina de imprenta a vapor que le permitió incrementar significativamente su tiraje, sin embargo no será hasta 1889 que la prensa escrita se popularice con el diario El Día que será el primero en editarse a un muy bajo costo y por lo tanto con gran presencia en la venta de calle.

A fines del siglo XIX comienza a aumentar la proporción de la publicidad, se transforma el negocio gráfico, con un gran número en aumento de ilustraciones y grandes titulares. La forma de transmitir la publicidad a través de la prensa, convierte a esta última en uno de los medios masivos de comunicación más importante en la época a estudiar. Hacen parte de los servicios, en la estructura capitalista hacen parte del sector terciario, y sirven también como indicadores sociales. Tal como señala Faraone (1969), existe una relación directa entre la cantidad de prensa escrita vendida cada 100 habitantes, con la tasa de analfabetismo de la población, ello es explicativo de que dicha relación es producto de las complejas relaciones materiales, y no simplemente de un vínculo "cultural".

Los diarios de la ciudad de Montevideo, al concentrarse en ella la mayor cantidad de población del país, en el momento de desarrollo de la prensa, se convierten en periódicos nacionales, no obstante muchas localidades del país, cuentan con su propia prensa, como el caso de la ciudad de Rivera. En general contienen espacios para diversos sectores, como entretenimiento, información, opinión, y publicidad, que se expresa a través de un lenguaje articulado oral o escrito, por imágenes o símbolos gráficos, transmiten valores, impulsan conductas y actitudes.

Tanto la publicidad, como la propagada hacen parte de la lógica capitalista, este sistema es competitivo de producción y utiliza la publicidad para incentivar las ventas, acentuando así las reglas de competitividad productiva, que generan un constante crecimiento 
en la cantidad de productos fabricados, reduciendo los costos y permitiendo enfrentar a los competidores de mercaderías similares (FARAONE, 1969).

\section{4- Metodología y técnicas}

Esta investigación es de carácter cualitativo y resulta indispensable para su desarrollo partir desde una perspectiva interpretativa y de análisis del lenguaje, ya que es el instrumento de mediación en la comprensión del objeto de estudio, siguiendo lo que plantea Jesús Ibáñez "el lenguaje funciona como equivalente general de valor...de todas las practicas significantes" (IBÁÑEZ, 1986, p.41). Expresa además que el lenguaje no solo es una herramienta para investigar a la sociedad sino que es "el objeto propio del estudio: pues, al fin y al cabo, el lenguaje es lo que la constituye o al menos es coextensivo con ella en el espacio y en el tiempo" (IBÁÑEZ, 1986, p.42). Adoptamos por lo tanto esta postura epistemológica si queremos acercarnos y lograr una interpretación y comprensión del sistema discursivo de la publicidad. Ello se hace explícito mediante el estudio de los distintos códigos lingüísticos presentes en los documentos estudiados, permitiéndonos conocer dicho discurso dentro del espacio y tiempo en que se encuadra la misma.

Dentro del análisis de documentos además del lenguaje ya mencionado, es necesaria una crítica externa, en donde lo situamos dentro de su propio contexto y conjunto de circunstancias, económicas, sociales y tecnológicas de la época que es producto tal como plantea López (2002), ello nos permitirá descubrir el valor del mensaje publicitario y el impacto del mismo. Así como también la crítica interna al contrastar e interpretar los mensajes de los distintos documentos estudiados, lo que nos permitió conocer la secuencia y elementos característicos del discurso que se van manteniendo con el transcurso del tiempo y nos permiten explicarlo.

A su vez para complementar el análisis documental y poder generar una mejor interpretación realizamos algunas entrevistas en profundidad. Optamos por un formato semiestructurado de entrevista con su correspondiente guía para asegurarnos así que los temas claves de la investigación sean explorados, la guía de entrevista siguiendo lo planteado por Taylor y Bogdan (1994) permitirá que se cubran con cada informante las áreas generales que se deben tratar para alcanzar los objetivos de la investigación pero proporcionará la flexibilidad necesaria.

\section{5- Hallazgos}


Como ya hemos dejado explicitado a lo largo del presente artículo nos encontramos con que sobre la publicidad y su historia a nivel mundial mucho ya se ha escrito, sin embargo sobre el departamento y la ciudad de Rivera estamos muy lejos de poseer una vasta colección bibliográfica sobre la historia en general del departamento y mucho menos sobre su publicidad comercial. La historiografía nacional está construida fundamentalmente desde Montevideo y concentrada sobre sus zonas y departamentos aledaños. Ello trajo como consecuencia que una vez planteado nuestro interés por investigar el tema de la publicidad comercial riverense entre 1914 y 1920 y dada la inexistencia de publicaciones al respecto, se nos hizo necesario realizar una recopilación de materiales bibliográficos sobre la publicidad en general durante la etapa de fines del siglo XIX y comienzos del XX, así como de la coyuntura internacional de aquel momento, aspectos aquí ya mencionados que nos permitieran tener una base teórica para interpelar lo que fuéramos hallando. Luego, de fundamental importancia fue el acceso al material de archivo del Museo del Patrimonio Regional de Rivera, en dónde nos encontrarnos con una importante cantidad de archivos de prensa escrita, ante el tan amplio abanico de posibilidades decidimos concentrarnos en los archivos del desaparecido periódico "El Comercio" que tenía como su director entre esos años a Juan E. de Carlos y como administrador a Alejandro de Carlos, hijo. En este medio de prensa existen una importante cantidad de publicidad, allí comerciantes o prestadores de servicios tanto de Rivera como de Livramento utilizaban sus páginas como medio de difusión.

Fue al recorrer sus páginas que nos encontramos con que "El Comercio" fue el agente publicitario de la casa "La Bella Vista", de la ciudad de Rivera. Desde 1914 en cada edición del mismo estaba presente una publicidad que hacía alusión a dicha casa comercial, que desde que comenzó la Primera Guerra Mundial experimentó algunos cambios en su formato, que nos resultaron muy llamativos lo cual nos terminó por decidir a enfocar nuestro estudio en dicha publicidad. Debido a que no contamos con material bibliográfico específico nos volcamos a recopilar todos los datos posibles así como bibliografía general que nos permitirán acercarnos a nuestro objeto de estudio que es la publicidad y en concreto el análisis de su discurso que se desprende a través de su diseño y se pone de manifiesto a través de dicha publicidad.

\section{6- La publicidad, un caso particular.}

Para poder realizar un análisis del discurso de la publicidad a tratar en específico, es necesario tener en cuenta algunos datos sobre la casa comercial. El dueño de la casa La Bella Vista, era Juan José Molke, proveniente del Líbano territorio del Imperio Otomano por aquel 
entonces, el comercio se ubicaba sobre Avenida Sarandí esquina Cuñapirú (actual Calle Lavalleja, hoy está instalada una automotora en dicha ubicación).

[...] Juan Molke, establecido en Rivera desde los primeros años del siglo XX , respetado y exitoso comerciante que recibió muchas parejas y solteros jóvenes enviados en su recomendación por parte de los padres o amigos. Molke fue reconocido como una especie de cónsul y el asesor de la comunidad de la diáspora libanesa en esta región (CHIPOLLINO, 2014, p.4).

Teniendo en cuenta el reconocimiento que tuvo Molke, en su época y datos aportados por descendientes de personas vinculadas a él, se puede deducir la importancia del comercio para la región en el momento que se realiza el estudio. Molke además de ser un personaje relevante de la sociedad de Rivera, así también lo revelan los primeros sondeos de personas entrevistadas, utiliza sus cualidades en la publicidad comercial, "el publicitario empleará su magia y la sugestión, el argumento y la retórica, todo ello mezclado con un mensaje llamativo, seductor, fascinante” (MOLES y COSTA, 2005, p. 18).

La publicidad del periódico "El Comercio" es una continuación de la misma lógica del sistema capitalista que rige la producción de los productos que se difunden a través de sus páginas, consistía en avisos publicitarios; y los avisos como tales se basan en lo que Moles y Costa (2005) llaman una "doble dialéctica" o "doble juego complementario" que consiste en una imagen que raras vez es precisa, conduciendo así a diferentes interpretaciones, es por lo tanto "polisémica", a su vez en este juego dialéctico se encuentra el texto más débil que la imagen porque exige un mayor esfuerzo intelectual por otra parte es más preciso o posee al menos dicha intención, habitualmente se halla en el mismo un argumento y en este sentido es "monosémico", o por lo menos posee un menor número de significados con respecto a la imagen. En la publicidad de "La Bella Vista" hay una doble dialéctica, es identificable en varios de sus avisos publicitarios a modo de ejemplo el aviso del 6 de enero de 1914 que ocupa una página, hace uso de elementos decorativos que ayudan a centrar la vista en lo que actualmente llamaríamos el logotipo del comercio al cual sigue un texto largo de carácter argumentativo retórico.

Por otra parte, en los avisos del mes de mayo de 1914 que continúan ocupando una página entera se resalta en letras grandes inmediatamente debajo del encabezado a la altura de los ojos del lector al pasar la página "Economizan Todos” y casi a media página "Aleluya! Siempre Aleluya!" que actúan en conjunto con elementos decorativos dichas imágenes ayudan a centrar la atención en las palabras que operan como titulares seguidas en el primer 
caso de una cita de la Divina Comedia que da pie al texto en el que alude a las ventajas de realizar compras en dicho comercio.

Los avisos publicitarios desde agosto de 1914 hasta marzo de 1915 también ocupan una página entera con un estilo similar, inmediatamente debajo del encabezado se destaca en letras grandes "La Conflagración de las Potencias Europeas" a imitación de titular de una noticia y haciendo alusión a la Primera Guerra Mundial que transcurre en dicho momento. El aviso se complementa con un texto en el cual hace amplio uso de metáforas, dónde "La Bella Vista” se convierte en una Potencia más de su época y luego en una institución bancaria, utilizando recursos argumentales para destacar sus productos y precios de forma muy ingeniosa y original.

La lógica del diseño que imita una noticia se mantendrá en el aviso publicitario que comenzó a aparecer en marzo de 1915, en el cual encabezando la página y en forma de arco se dispondrá en letras grandes a modo de titular "Colosal Conmemoración" de "La Bella Vista" y en letras algo menores "Por la Derrota de las Huestes Musulmanas" a lo que sigue debajo el texto para convencer a los clientes de sus precios convenientes y cierra con una evocación poética en donde se mezcla lo artístico con lo comercial y las referencias a la guerra que sacude al mundo en dicha época.

En todos los avisos publicitarios que mencionamos de "La Bella Vista", se percibe una cuidadosa elección en el diseño las dimensiones y la disposición de los elementos dentro de la publicidad, estando estos además ordenados jerárquicamente teniendo en cuenta lo que pueda ser más importante para los potenciales lectores. Los avisos de "La Bella Vista" se presentan como noticia porque obedecen a la lógica de su soporte el periódico y su diseño por la forma del acto de lectura y uso de un medio de prensa escrito, el alcance de dicha publicidad en la esfera familiar y laboral de la época queda explicitada en el aviso publicitario del 3 de enero de 1914 en el cual se hace referencia a la conveniencia para los "bolicheros", "comercio de campaña y "a las familias" de realizar sus compras en dicho local. En la misma publicidad están aún muy presentes las alusiones a la crisis desatada en 1913, tal como explican Barrán y Nahum (1977b) durante esa época las guerras balcánicas, el temor a la guerra entre las potencias europeas y la crisis financiera en los Estados Unidos provocaron una reducción del crédito mundial desatando la crisis. Debido al cierre del crédito externo, hubo una elevación de las tasas de interés o directamente la no otorgación créditos a particulares, durante este período las reservas del Banco República en especial disminuyeron de manera notable, hubo corridas para realizar conversiones a oro y pánico en las sucursales del Banco, el sector de los industriales, comerciantes y productores rurales se vio 

e-ISSN 2016/Atual: 2525-7870 | e-ISSN 2015/2016: 2447-018X

especialmente afectado por las medidas de restricción del crédito y menor cantidad de dinero en circulación. Sin embargo en la publicidad citada utiliza estas consecuencias de la crisis a su favor.

En la publicidad de agosto de 1914 y que se mantendrá hasta marzo del año siguiente aparecen referencias al contexto comercial y financiero del momento, así como a otro elemento de la mentalidad de la época, el anhelo de seguridad en materia financiera, durante este período la publicidad de "La Bella Vista" que metafóricamente se convierte en un Banco se presenta como un "coloso" financiero que no realiza inconversiones perjudiciales y que no genera recargos, aceptando dinero papel despreciando al oro. Tal como señalan Barrán y Nahum durante la primera década del siglo XX una importante suma de capitales en libras esterlinas se concentraba en Uruguay fundamentalmente en Montevideo en manos de fuertes comerciantes y propietarios de tierras a lo que añaden "esa angustiosa búsqueda de la seguridad llevo a los rurales a rechazar siempre que podían el billete papel sobre todo y será del Banco del Estado, prefiriendo la incómoda pero firme libra esterlina de oro" (BARRÁN y NAHUM, 1977a, p.396). Estos autores explican además que en el interior a pesar de la existencia de sucursales del Banco República existía una gran desconfianza en utilizar sus billetes o realizar las conversiones de moneda fuerte en moneda nacional. Este conservadurismo en materia financiera es revelador de los denominadores psicológicos para tal práctica el atesoramiento y la posesión, elementos distintivos de una mentalidad aún con fuerte arraigo en la tradición (BARRÁN y NAHUM, 1977a). Por otra parte, dicha publicidad no sólo deja entrever estos elementos de orden psicológico-social, sino que también refleja el clima de incertidumbre que reina a nivel del comercio riverense, un artículo publicado en el mismo periódico durante ese mismo mes en que aparece dicha publicidad comentaba al respecto:

El comercio nacional, y muy particularmente el de toda esta frontera, cruza hoy uno de los períodos más difíciles, que haya podido traerle la tenaz y perturbadora crisis, agravado por las contingencias producidas por la comunión económica de los mercados europeos. En el año 1913, a pesar de los fatales augurios a que la gravedad del asunto dio lugar (...) el comercio local conjuro tan recias acometidas, salvando lo mejor que le fue posible, las consecuencias funestas (...) Y al fin del año del maleficio, el comercio de Rivera se encontró en pie, pero exhausto, maltrecho (...) sostenido tan sólo por la esperanza de una pronta y saludable reacción (...) Pero vino el año 14 (...) sin que aquella esperanza se realizase, viene por el contrario, la guerra internacional, viene el cambio del régimen financiero de la República ( ..... ${ }^{3}$

\footnotetext{
${ }^{3}$ Extraído de "El Comercio" 21 de agosto de 1914, №190.
} 

e-ISSN 2016/Atual: 2525-7870 | e-ISSN 2015/2016: 2447-018X

En el artículo, es clara la alusión al decreto que el Poder Ejecutivo aplicó al estallar la guerra, imposibilitando realizar conversiones en metálico, así como la clara incidencia que tenía sobre la economía nacional y por lo tanto también en el comercio local la dependencia con respecto a las economías centrales. La publicidad de "La Bella Vista" recoge todos estos hechos que sin duda tenían gran repercusión y son utilizados en su estrategia publicitaria.

En los anuncios publicitarios estudiados desde marzo de 1915 hasta octubre de 1916, son constantes las referencias de carácter religioso, con una muy ingeniosa forma en la publicidad, son continuas las alusiones a los valores cristianos en los cuales "La Bella Vista" se presenta como generosa, altruista y dispuesta al sacrifico en beneficio de sus clientes, en efecto durante marzo de 1915 y durante un año se presentará cual noticia y en festejo de las derrotas del Imperio Otomano en la Primera Guerra Mundial a los cuales alude como la "hueste musulmana" y los "súbditos del Sultán de Turquía”.

Desde marzo hasta octubre de 1916 la publicidad hace referencias explicitas al Profeta bíblico Moisés y la jornada del Éxodo en la cual "La Bella Vista" encarna una especie de nuevo Moisés que conduce a sus clientes a una tierra de promisión de los precios bajos, también resalta que no hace acepción de personas ya sean pobres o ricos, estos elementos publicitarios son una clara alusión a la religión de su propietario e ideólogo de su publicidad; que así como la gran mayoría de los inmigrantes libaneses, asentados en la ciudad de Rivera por aquel entonces eran cristianos católicos maronitas, según nos relató uno de nuestros entrevistados quién al ser indagado sobre la identificación de los inmigrantes libaneses como turcos por parte de la población local de aquel entonces agregó: "era una ofensa para ellos ser llamados de turcos, eran católicos maronitas".

\section{7- Reflexiones finales}

La publicidad no está completamente separada de la propaganda tal como lo plantea Pizarrozo (1999) y en este aspecto es patente su intencionalidad de servir además como elemento propagandístico en el sentido que alude Méndiz (2008) de propagar aquellas ideas transcendentales para las personas, en este caso desasociar a "La Bella Vista" y por ende a su propietario del calificativo de turco tan comúnmente empleado para referirse a los inmigrantes libaneses de la época por la población local, es así la publicidad un elemento de lo que Mijaíl Bajtín (BAJTÍN, s/f Apud BURKE, 2004) denomina poliglosia o mejor dicho las diferentes voces en un mismo texto, la publicidad de "La Bella Vista" por lo tanto manifiesta la voz del fuerte comerciante que desea vender sus productos al público, pero que de modo muy 
particular también es la del inmigrante libanés que reivindica sus orígenes y valores culturales.

Teniendo en cuenta hasta el punto que avanza nuestra investigación, las palabras expresadas anteriormente en base al análisis de la publicidad de la "Casa Bella Vista", situado en el contexto que se menciona al principio de este artículo teniendo como base las consideraciones de Hobsbawm (2007) planteadas en el estado de arte, se puede deducir que la publicidad claramente es una herramienta que utiliza el sistema capitalista para su afianzamiento y los cambios en las mismas son para dar una continuidad a la lógica que impera, esto claramente visible en la publicidad que aquí se analiza.

También es notable como la actividad comercial local configura a un territorio, en este caso la ciudad de Rivera se fue desarrollando lentamente dentro del proceso de modernización como señalan Barrán y Nahum (1977) y en ello influyó notablemente el comercio, ésta es una actividad que según Chipollino Aseff (2014) ayudó al crecimiento de la ciudad, y se expandió más allá del ejido de la misma, llegó a zonas rurales, distribuyendo así productos importados que llegaban a través de Rio Grande y del puerto de Montevideo a través del ferrocarril. Si tomamos al comercio, como un elemento estructurante de la sociedad riverense del período que se está estudiando, podemos dar cuenta de algunas de las características como un importante flujo migratorio establecido en la ciudad que se dedica a la actividad comercial establecidos algunos en Avenida Sarandí, y la mayoría en Avenida Brasil. Con su establecimiento se modificó el consumo de las personas, mejora la calidad de los artículos de primera necesidad, y llegan nuevos productos suntuosos, se deduce su impacto en la sociedad debido al gran número de anuncios publicitarios en los periódicos de época, y en especial la que es objeto de estudio, en ella está explicita las intenciones del dueño del ese comercio, por lo tanto la publicidad es un medio de dominación a través de la cual se ejerce un poder simbólico, transmite un discurso con la intención de incitar al consumo, y cumple una función de disciplinamiento, imperante en la producción del discurso. Siguiendo las ideas de Foucault (1970), la publicidad es una forma de discurso que se pone en práctica, mediante periódicos que llegan a diversos los sectores de la sociedad.

El discurso también actúa como una representación, partiendo de la base de la teoría de Stuart Hall (1997) el lenguaje expresado a través de un discurso es compartido por una sociedad específica generándose así una sistematización de conceptos que representan a dicha sociedad en determinada época. En el caso de la publicidad riverense el consumo, ahorro, crisis son conceptos compartidos tanto por el dueño de la casa "Bella Vista" como por compradores, a quién va dirigido el discurso de la publicidad que utiliza argumentos citados 
anteriormente para causar un impacto al público. La relación entre el discurso y la cultura, es que a través de él se produce la sistematización de conceptos claves para entender una época, como la que se encuentra en cuestión; los conceptos serán compartidos por los diferentes actores sociales que comparten una misma cultura, en este caso la sociedad fronteriza en relación a la forma de sentir la crisis cuando la publicidad hace mención a la crisis y como ésta es transmitida a la sociedad riverense a través de una casa comercial.

Teniendo en cuenta los planteos anteriores la publicidad y las ofertas regulan el consumo en una época de crisis, como la que hace alusión la publicidad de la casa "Bella Vista”. A través del discurso se emplea el poder que permea todos los aspectos de la sociedad, evidente en relación a los descuentos y vender más barato para atraer a un público utilizándolo mediante la persuasión a través del discurso de la publicidad, lo que también deja en claro la lucha de clases.

\section{Referências}

BARRÁN, J. Pedro; NAHUM. B.; "Historia rural del Uruguay Moderno" Tomo VI. Montevideo: Ediciones de la Banda Oriental, 1977. 215p.

BARRÁN, J.Pedro; NAHUM, B. "Historia rural del Uruguay Moderno" Tomo V, Montevideo: Ediciones de la Banda Oriental, 1977b. 171p.

BERTOLA, L.; OCAMPO, J.A. "Desarrollo económico de América Latina desde la Independencia”. México: FCE, 2013. 303p.

BURKE, P. “Qué es la Historia Cultural”. Barcelona: Paidós, 2004. 163p.

CARDOSO, F; FALLETO, E. "Dependencia y desarrollo en América Latina". Buenos Aires: Siglo XXI, 2011. 65p.

CHIPOLLINO ASSEF, L. "Um olhar sobre a presença árabe na Fronteira" Estudios Historicos - CDHRPyB, Uruguay, Año VI, No 12, 2014. Traducción libre. 12p.

FARAONE, R. "Medios masivos de comunicación” Montevideo: Nuestra tierra 25, 1969. $64 p$.

FOUCAULT, M. “El Orden del Discurso” Buenos Aires: Fabúla Tusquets, 1970. 76p.

HAESBAEET, R. "Del mito de la Desterritorialización a la multiterritorialidad", Cultura y representaciones sociales, $\mathrm{N}^{\circ} 15$, Año 8. 2013.34.

HALPERÍN Donghi, T. "Historia Contemporánea de América Latina" $1^{\circ}$ Ed. Madrid: Alianza, 1969.741.

HOBBSBAWM, E. “La Era del Imperio (1875-1914)”. Buenos Aires: Crítica, 2007. 389p. 

e-ISSN 2016/Atual: 2525-7870 | e-ISSN 2015/2016: 2447-018X

IBÁÑEZ, Jesús. "Más allá de la sociología. El grupo de discusión: técnica y crítica" Madrid: Siglo XXI, 1986. 428p.

LÓPEZ, F. "El análisis de contenido como método de investigación”. Revista de Educación, Huelva, 4, p.167-179, 2002.

MÉNDIZ, A. "Diferencias Conceptuales entre Publicidad y Propaganda: una aproximación etimológica". Questiones Publicitarias, Málaga, Vol. I, N 12, p.43-61, 2008.

MOLES, A; COSTA, J. "Publicidad y diseño. El nuevo reto de la comunicación." Buenos Aires: Ediciones Infinito, 2005. 159p.

PIZARROSO, A. "La historia de la propaganda: una aproximación metodológica.". Historia y Comunicación Social, Madrid, № 4, p.145-171, 1999.

QUIJANO, A (s/a) "Dependencia, cambio social y urbanización en Latinoamérica", s/e., versión digital.

STUART, Hall (1997) "Representation: cultural representations and signifying practices" Sage publications, Londres, Cap. 1 (pp.13-74). Traducción de Elías Sevilla Casas 2002.

TAYLOR, S.J; BOGDAN, R. "Introducción a los métodos cualitativos de investigación. La búsqueda de significados" 2 Ed. Barcelona: Paidós Básica, 1994. 301p. 